\title{
The Application of Grey Fuzzy Comprehensive Evaluation Method in Distribution Center Planning Scheme Optimization
}

\author{
Jingjing JIANG \\ Dept. of Information Technology and Business Administration \\ Dalian Neusoft Institute of Information \\ Dalian, China, 0411-84835228 \\ jiangjingjing@neusoft.edu.cn \\ Tingbin CHEN \\ Dept. of Information Technology and Business Administration \\ Dalian Neusoft Institute of Information \\ Dalian, China
}

\begin{abstract}
At present, the planning of distribution center is a very important step before the construction. Therefore, how to choose the optimal plan in the process of the planning of distribution center has already become an important research topic in logistical system. In this paper, Grey Fuzzy Comprehensive Evaluation (GFCE) method is proposed to resolve the optimization problem.
\end{abstract}

Keywords-planning of distribution center; Grey Fuzzy Comprehensive Evaluation(GFCE) ; optimization

\section{INTRODUCTION}

With the booming logistics industry, the grey fuzzy comprehensive theory has been widely applied, but so far the method has been rarely involved in the distribution center planning scheme optimization. Therefore, the application of grey fuzzy theory to solve the optimization problem of distribution center planning scheme is necessary and meaningful.

A business case is cited in this paper, using grey fuzzy comprehensive evaluation method to establish the index system and model of the distribution center planning scheme and to solve the problem of scientific planning scheme optimization. The successful application of grey fuzzy comprehensive evaluation theory in this case, proving the effectiveness and reliability of the method, not only plays an important role of reference and guidance for decision-making of building a distribution center in some logistics enterprises, but also opens up a new way of thinking for the application of grey fuzzy comprehensive evaluation theory in the logistics industry.

\author{
Xiaoyu WANG \\ Dept. of Information Technology and Business Administration \\ Dalian Neusoft Institute of Information \\ Dalian, China \\ Xiangwei MU \\ Transportation Management College \\ Dalian Maritime University \\ Dalian, China, 0411-84728928 \\ xiangwei.mu@gmail.com
}

\section{GREY FUZZY COMPREHENSIVE EVALUATION THEORY AND METHODS}

\section{A. Fuzzy Comprehensive Evaluation Model}

Multi-objective fuzzy comprehensive evaluation method, mainly using of evaluation results of single factor related to the evaluation object, is to form the corresponding evaluation matrix, and to do fuzzy transformation using the weighting factor for determining the important degree of each factor, and the final evaluation results of the evaluation object will be obtained. Multi-factor fuzzy evaluation set is determined by the use of the factor set, membership degree, weighting factor, and the best evaluation results will be obtained from the alternative set ${ }^{[1]}$.

Comprehensive evaluation is recorded as:

$$
B=\left\{b_{1}, b_{2}, \cdots, b_{n}\right\}=\left(a_{1}, a_{2}, \cdots, a_{m}\right) \circ\left[\begin{array}{cccc}
r_{11} & r_{12} & \cdots & r_{1 n} \\
r_{21} & r_{22} & \cdots & r_{2 n} \\
\cdots & \cdots & \cdots & \cdots \\
r_{m 1} & r_{m 2} & \cdots & r_{m n}
\end{array}\right]
$$

In the formula, $b_{n}$ reflects the position occupied by the n-th decision in the evaluation overall, and $\mathrm{a}_{\mathrm{m}}$ means the weights of various factors, and $r_{i j}$ means the normalized result that is obtained by respectively converting single factor evaluation set into membership degree of each single factor according to membership functions of single factor fuzzy sets. The operator "०» is a fuzzy one.

$$
\begin{gathered}
+\quad+ \\
b_{j}=\left(a_{1} * r_{1 j}\right) *\left(a_{2} * r_{2 j}\right) * \ldots *\left(a_{m} * r_{m j}\right) j=(1,2 \cdot \cdots n)
\end{gathered}
$$


In the formula, * is the generalized fuzzy "and" operator, and $_{*}^{+}$is the generalized fuzzy "or" operator ${ }^{[2]}$.

\section{B. Grey Comprehensive Evaluation Method}

1) Concepts and Principles of Grey Correlation Analysis

Grey correlation analysis, as a quantitative one on the development trend of dynamic process, is based on grey process of the grey system. It mainly does research on the dynamic process using curve geometry analysis method. The view is the closer curve geometry is, the closer the trend of change and development is, and the higher the correlation degree is ${ }^{[3]}$.

\section{2) Calculate Correlation Degree ${ }^{[4-5]}$}

The correlation degree of two comparative sequences can be expressed as the average of correlation coefficient of the two sequences in each moment. The mathematical model is as follows:

If there are $n$ parent sequences $Y_{1}, Y_{2}, Y_{3}, \cdots Y_{n} \quad n \neq 1$ and $m$ sub- sequences $X_{1}, X_{2}, X_{3}, \cdots X_{m} \quad m \neq 1$, then the correlation degree of each subsequence associated with parent sequences is

$$
\begin{gathered}
\left(r_{11}, r_{12}, \cdots, r_{1 m}\right) \\
\left(r_{21}, r_{22}, \cdots, r_{2 m}\right) \\
\vdots \\
\left(r_{n 1}, r_{n 2}, \cdots, r_{n m}\right)
\end{gathered}
$$

Make the appropriate arrangement for $r_{i j}(i=1,2, \cdots, n ; j=1,2, \cdots, m)$, and the correlation matrix will be got.

$$
R=\left[\begin{array}{cccc}
r_{11} & r_{12} & \cdots & r_{1 \mathrm{~m}} \\
r_{21} & r_{22} & \cdots & r_{2 \mathrm{~m}} \\
\cdots & \cdots & \cdots & \cdots \\
r_{n 1} & r_{n 2} & \cdots & r_{n \mathrm{~m}}
\end{array}\right] \text { or } R=\left[\begin{array}{cccc}
r_{11} & r_{12} & \cdots & r_{1 n} \\
r_{21} & r_{22} & \cdots & r_{2 n} \\
\cdots & \cdots & \cdots & \cdots \\
r_{m 1} & r_{m 2} & \cdots & r_{m n}
\end{array}\right]
$$

Correlation matrix can be used as the basis of the correlation analysis. If the formula (5) is established as follows.

$$
\frac{1}{n} \sum_{k=1}^{n} r_{k i}>\frac{1}{n} \sum_{k=1}^{n} r_{k j} i, j=1,2, \cdots m \text { and } i \neq j
$$

The view is the correlation degree of the parent sequence $Y_{i}$ relative to the other parent sequences or sub-sequence $x_{i}$ is quasi optimal.

\section{THE APPLICATION OFGREY FUZZY COMPREHENSIVE EVALUATION IN DISTRIBUTION CENTER PLANNING SCHEME OPTIMIZATION}

\section{A. Establishment of Index System}

The company has three distribution center planning options, respectively scheme $\mathrm{A}$, scheme $\mathrm{B}$ and scheme $\mathrm{C}$. In this paper, scheme selection is mainly focus on 13 factors. There is no consideration for other factors as their weights are too small to ignore their impact of the evaluation model. Index is based on three different levels, namely economy index, technology index and system operation index ${ }^{[6]}$. Index system is shown in table 1.

TABLE 1. Evaluation index system of distribution center

\begin{tabular}{|c|c|c|}
\hline \multicolumn{3}{|c|}{ Comprehensive Evaluation of The Distribution Center Planning Scheme } \\
\hline $\begin{array}{c}\text { Economy Index } \\
\boldsymbol{B}_{\mathbf{1}}\end{array}$ & $\begin{array}{c}\text { Technology Index } \\
\boldsymbol{B}_{2}\end{array}$ & $\begin{array}{c}\text { System Operation Index } \\
\boldsymbol{B}_{3}\end{array}$ \\
\hline Land Area & $\begin{array}{c}\text { Equipment maintenance } \\
\mathrm{O}_{1}\end{array}$ & $\begin{array}{c}\text { Storage flexibility } \\
\mathrm{O}_{6}\end{array}$ \\
\hline Warehouse Building & $\begin{array}{c}\text { Equipment reliability } \\
\mathrm{O}_{2}\end{array}$ & $\mathrm{O}_{7}$ \\
\hline Equipment Cost & $\begin{array}{c}\text { Operational flexibility } \\
\mathrm{O}_{3}\end{array}$ & $\mathrm{O}_{10}$ \\
\hline Labor Cost & $\mathrm{O}_{8}$ & System scalability \\
$\mathrm{O}_{4}$ & & $\mathrm{O}_{11}$ \\
\hline Energy consumption & & Personnel security \\
$\mathrm{O}_{5}$ & & $\mathrm{O}_{12}$ \\
\hline
\end{tabular}

Among them, $A$ is the target layer, and $B_{i}(i=1,2,3)$ is the first level index, $\mathrm{O}_{\mathrm{j}}(\mathrm{j}=1,2, \ldots, 13)$ is the second level index.

\section{B. Distribution Center Planning Scheme Model and Solving}

\section{1) Use AHP Method to Determine Index Weight}

a) Determine the weights of the first layer indexes ${ }^{[7-9]}$

Use AHP method to establish evaluation matrix and calculates according to the importance among the layers of subtarget including economy index, technology index and system operation index. The weights of the three layers of sub-target are determined by their relative importance. Specific evaluation method is as follows.

According to the survey of users' and experts' scores, make comparison between each two sub-targets in relative to the total target. The first layer evaluation matrix A will be established according to Seaty scale principle.

\begin{tabular}{|c|c|c|c|}
\hline $\mathbf{A}$ & $\mathbf{B}_{\mathbf{1}}$ & $\mathbf{B}_{\mathbf{2}}$ & $\mathbf{B}_{\mathbf{3}}$ \\
\hline $\mathbf{B}_{\mathbf{1}}$ & 1 & 5 & 3 \\
\hline $\mathbf{B}_{\mathbf{2}}$ & $1 / 5$ & 1 & $1 / 3$ \\
\hline $\mathbf{B}_{\mathbf{3}}$ & $1 / 3$ & 3 & 1 \\
\hline
\end{tabular}

I. Calculate the product of elements of each row in the matrix above

$$
M_{i}=\prod_{j=1}^{n} b_{i j} \quad(\mathrm{i}=1,2, \cdots, \mathrm{n})
$$

II. Calculate the $\mathrm{n}$-th root of $\mathrm{Mi}$

$$
\bar{W}_{i}=\sqrt[n]{M_{i}} \quad(\mathrm{i}=1,2, \cdots, \mathrm{n})
$$

III. Vector $\bar{W}=\left[\bar{W}_{1}, \bar{W}_{2}, \cdots, \bar{W}_{n}\right]^{T}$ normalization

$$
W_{i}=\frac{\bar{W}_{i}}{\sum_{i=1}^{n} \bar{W}_{i}} \quad(\mathrm{i}=1,2, \cdots, \mathrm{n})
$$

According to three formulas above, the weights of economy index, technology index and operating system index relative to the target layer are calculated.

$$
W=\left[W_{B 1}, W_{B 2}, W_{B 3}\right]=[0.637,0.105,0.258]
$$


Through having the consistency test, calculate consistency ratio C.R. is 0.33 , less than 0.1 , and the result indicates the first layer evaluation matrix has satisfied consistency.

b) Determine the weights of the second layer indexes

As the same as the calculation of the weights of the first layer indexes, the weights of land area, warehouse building, equipment cost, labor cost and energy consumption relative to economy index are as follows.

$$
\left[W_{O_{1}}, W_{O_{2}}, W_{O_{3}}, W_{O_{4}}, W_{O_{5}}\right]=[0.410,0.253,0.134,0.134 .0 .069]
$$

The weights of Equipment maintenance, equipment reliability and degree of automation relative to technology index are as follows.

$$
\left[W_{O_{6}}, W_{O_{7}}, W_{O_{8}}\right]=[0.292,0.615,0.093]
$$

The weights of storage flexibility, operational flexibility, system scalability, personnel security and personnel quality needs are as follows.

$$
\left[W_{\mathrm{O}_{9}}, W_{\mathrm{O}_{10}}, W_{\mathrm{O}_{11}}, W_{\mathrm{O}_{2}}, W_{\mathrm{O}_{13}}\right]=[0.071,0.229,0.046,0.552,0.102]
$$

Through calculating consistency ratio, the result indicates the second layer evaluation matrix has satisfied consistency. Then multiply these weights by the weights of the first layer indexes, and get the weights of the thirteen indexes in the whole index system.

$$
\begin{aligned}
& W=\left[W_{1}, W_{2}, \cdots, W_{13}\right] \\
& =[0.26,0.16 .0 .09,0.09,0.04,0.03,0.06,0.01,0.02,0.06,0.01,0.14,0.03]
\end{aligned}
$$

Thus the weights of thirteen indexes in the second layer relative to the target have been calculated.

\section{2) Use Grey Model to Calculate Grey Weight}

a) Determine the evaluation sample matrix

Invite 10 experts in the field of distribution respectively give their scores for the 13 indexes in 3 different schemes. Make the rule that each score range is from 1 to 10 , and expert evaluation sample matrix is finished.

As shown in Table 2, the score of each evaluation index in scheme $\mathrm{A}$ is given.

TABLE 2. Score of each index in scheme A

\begin{tabular}{|c|c|c|c|c|c|c|c|c|c|c|c|c|c|}
\hline $\mathbf{d}_{\mathbf{i}}$ & $\mathbf{O}_{\mathbf{1}}$ & $\mathbf{O}_{\mathbf{2}}$ & $\mathbf{O}_{\mathbf{3}}$ & $\mathbf{O}_{\mathbf{4}}$ & $\mathbf{O}_{5}$ & $\mathbf{O}_{\mathbf{6}}$ & $\mathbf{O}_{\mathbf{1}}$ & $\mathbf{O}_{\mathbf{8}}$ & $\mathbf{O}_{\mathbf{3}}$ & $\mathbf{O}_{\mathbf{1}}$ & $\mathbf{O}_{\mathbf{I l}}$ & $\mathbf{O}_{\mathbb{L}}$ & $\mathbf{O}_{\mathbf{B}}$ \\
\hline $\mathbf{E}_{\mathbf{1}}$ & 7 & 3 & 8 & 9 & 8 & 7 & 5 & 8 & 6 & 6 & 9 & 7 & 7 \\
\hline $\mathbf{E}_{\mathbf{2}}$ & 6 & 8 & 8 & 7 & 7 & 8 & 6 & 6 & 6 & 7 & 6 & 6 & 8 \\
\hline $\mathbf{E}_{\mathbf{3}}$ & 5 & 7 & 9 & 8 & 9 & 6 & 5 & 3 & 7 & 7 & 7 & 8 & 7 \\
\hline $\mathbf{E}_{\mathbf{4}}$ & 8 & 6 & 7 & 9 & 7 & 5 & 8 & 7 & 5 & 8 & 5 & 5 & 9 \\
\hline $\mathbf{E}_{\mathbf{5}}$ & 9 & 7 & 5 & 8 & 9 & 9 & 9 & 6 & 8 & 5 & 8 & 6 & 8 \\
\hline $\mathbf{E}_{\mathbf{6}}$ & 7 & 8 & 7 & 8 & 9 & 8 & 7 & 7 & 9 & 9 & 6 & 7 & 7 \\
\hline $\mathbf{E}_{\mathbf{7}}$ & 5 & 7 & 6 & 9 & 6 & 7 & 6 & 7 & 5 & 7 & 7 & 8 & 9 \\
\hline $\mathbf{E}_{\mathbf{8}}$ & 8 & 8 & 6 & 5 & 6 & 6 & 6 & 9 & 7 & 8 & 9 & 6 & 9 \\
\hline $\mathbf{E}_{\mathbf{9}}$ & 7 & 5 & 7 & 8 & 9 & 5 & 5 & 9 & 8 & 7 & 5 & 9 & 7 \\
\hline $\mathbf{E}_{\mathbf{1 0}}$ & 9 & 8 & 8 & 7 & 6 & 8 & 7 & 8 & 3 & 5 & 7 & 7 & 6 \\
\hline
\end{tabular}

The evaluation sample matrix calculation method for scheme B and C is the same with scheme A.

\section{b) Determine the evaluation grade}

Determine four evaluation grades are excellent, good, medium and bad based on the description of rules and evaluation requirements for the above indexes. Give scores for the four grades according to 10-point scale, and the evaluation grade set is determined.

$$
V=\left[V_{1}, V_{2}, \cdots V_{4}\right]=[9,7,5,3]^{T}
$$

c) Determine the evaluatio grey scale ${ }^{[10]}$

Determine the evaluation grey scale is to determine the numbers of grey grade, grey numbers and whitenization weight function for grey numbers.

The turning point value for whitenization weight function is called the threshold $d_{1}, d_{2}, d_{3}$. Get four domain values $9,7,5$, 3 according to the relative domain value method. The corresponding grey number and whitening function are as follows.

$$
\begin{aligned}
& f_{1}\left(d_{l i}\right)=\left\{\begin{array}{ll}
\frac{d_{l i}}{9} & d_{l i} \in[0,9] \\
1 & d_{l i} \in[9, \infty) \\
0 & d_{l i} \notin[0, \infty)
\end{array} \quad f_{2}\left(d_{l i}\right)=\left\{\begin{array}{cc}
\frac{d_{l i}}{7} & d_{l i} \in[0,7] \\
2 \frac{d_{l i}}{7} & d_{l i} \in[7,14] \\
0 & d_{l i} \notin[0,14]
\end{array}\right.\right. \\
& f_{3}\left(d_{i i}\right)=\left\{\begin{array}{cc}
\frac{d_{l i}}{5} & d_{l i} \in[0,5] \\
2 \frac{d_{l i}}{5} & d_{l i} \in[5,10] \\
0 & d_{l i} \notin[0,10]
\end{array} f_{4}\left(d_{l i}\right)=\left\{\begin{array}{cc}
1 & d_{l i} \in[0,3] \\
2-\frac{d_{l i}}{3} & d_{l i} \in[3,6] \\
0 & d_{l i} \notin[0,6]
\end{array}\right.\right.
\end{aligned}
$$

\section{d) Calculate the grey statistics}

Obtain the weight $f_{j}\left(d_{l i}\right)(1 \leq j \leq 4)$ which is $d_{l i}$ belonging to the $\mathrm{j}$-th evaluation criteria using the whitenization weight function for grey numbers in grey statistical method. Accordingly calculate grey statistics denoted as $n_{i j}$ and total grey statistics denoted as $n_{i}$ of the evaluation matrix.

$$
\begin{aligned}
& n_{i j}=\sum_{l=1}^{10} f_{j}\left(d_{l i}\right) \\
& n_{i}=\sum_{j=1}^{4} n_{i j}
\end{aligned}
$$

Take scheme A for example, according to the formula (9), grey statistics matrix is calculated as follows.

$$
\left(n_{A j}\right)_{13 \times 4}=\left[\begin{array}{cccccccccccccc}
7.89 & 7.44 & 7.89 & 8.67 & 8.44 & 7.67 & 7.11 & 7.78 & 7.11 & 7.67 & 7.67 & 7.67 & 8.56 \\
8.43 & 8.43 & 8.71 & 8.29 & 8.29 & 8.43 & 8.29 & 8.29 & 8.00 & 8.71 & 8.43 & 8.71 & 8.71 \\
5.8 & 5.8 & 5.8 & 4.4 & 4.8 & 6.2 & 7.2 & 5.2 & 6.4 & 6.2 & 6.2 & 6.2 & 4.6 \\
0.67 & 1.33 & 0.33 & 0.33 & 0.00 & 0.67 & 1.00 & 1.00 & 1.67 & 0.67 & 0.67 & 0.33 & 0.00
\end{array}\right]^{\mathrm{T}}
$$

Obtain the total grey statistics according to the formula (10).

$\left(n_{A}\right)_{131}=[227823.01227421 .6921 .53229623 .602226231823252296229121 .87]^{\mathrm{T}}$ 
Similarly, the total grey statistics of evaluation matrix of scheme B and C can be calculated.

$$
\begin{aligned}
& \left(n_{\mathrm{E}}\right)_{134}=[220621.6421 .46223222572291220522322210224623 .2323 .142246]^{\mathrm{T}} \\
& \left(n_{\mathrm{a}}\right)_{131}=[226823.0223 .5523 .132532229123 .5522962217229723 .1922962363]^{\mathrm{T}}
\end{aligned}
$$

e) Grey evaluation weight and weight matrix

Grey weight can be calculated according to formula (11).

$$
r_{i j}=\frac{n_{i j}}{n_{i}}
$$

Integrate grey weights which are the i-th evaluation factor arguing for the j-th evaluation criteria given by 10 experts. Single factor fuzzy evaluation weight matrix $\mathrm{R}$ which is composed of $r_{i j}$ is as follows.

$$
R=\left[\begin{array}{cccc}
r_{11} & r_{12} & \cdots & r_{1 m} \\
r_{21} & r_{22} & \cdots & r_{2 m} \\
\cdots & \cdots & \cdots & \cdots \\
r_{n 1} & r_{n 2} & \cdots & r_{n m}
\end{array}\right]
$$

Single factor fuzzy evaluation weight matrixes of the three schemes are calculated as follows.

$$
R_{A}=\left[\begin{array}{l}
0.3460 .3240 .3470 .4000 .3920 .3340 .3010 .3490 .3070 .3300 .3340 .3350 .391 \\
0.3700 .3660 .3830 .3820 .3850 .3670 .3510 .3720 .3450 .3750 .3670 .3800 .398 \\
0.2550 .2520 .2550 .2030 .2230 .2700 .3050 .2340 .2760 .2670 .2700 .2710 .210 \\
0.0290 .0580 .0150 .0150 .0000 .0290 .0420 .0450 .0720 .0290 .0290 .0150 .000
\end{array}\right]^{T}
$$

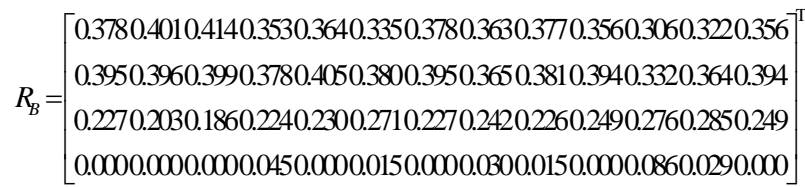

$$
R_{C}=\left[\begin{array}{l}
0.3430 .3380 .3020 .3170 .2980 .3350 .3020 .3340 .3560 .3390 .3260 .3340 .287 \\
0.3780 .3720 .3640 .3460 .3720 .3800 .3640 .3670 .3670 .3860 .3700 .3670 .332 \\
0.2650 .2610 .3060 .2940 .3160 .2710 .3060 .2700 .2620 .2610 .2760 .2700 .296 \\
0.0150 .0290 .0280 .0430 .0130 .0150 .0280 .0290 .0150 .0150 .0290 .0290 .085
\end{array}\right]^{\mathrm{T}}
$$

3) Use Fuzzy Mathematical to evaluate evaluation grade

a) Calculate the fuzzy comprehensive evaluation matrix $B$

The fuzzy comprehensive evaluation matrix $\mathrm{B}$ can be calculated based on compositional operation which is performed between weighted subset $\mathrm{W}$ and single factor fuzzy evaluation matrix R. $\sum_{i=1}^{m} b_{i}=1$ will be made by normalization. The fuzzy evaluation matrixes for three evaluation schemes are as follows.

$$
\begin{aligned}
& B_{A}=[0.35,0.37,0.25,0.03], \quad B_{B}=[0.37,0.39,0.23,0.01], \\
& B_{C}=[0.33,0.37,0.28,0.02] \\
& \text { b) Calculation the evaluation result } Z
\end{aligned}
$$

First, determine the grade matrix $C\left(C=\left[V_{1}, V_{2}, \cdots V_{m}\right]^{T}\right)$. Then, according to $\mathrm{Z}=\mathrm{BC}$, calculate the comprehensive evaluation result $\mathrm{Z}$. The evaluation for some scheme can be made by $\mathrm{Z}$ value. The bigger $\mathrm{Z}$ value is, the better the scheme is.

$$
Z_{A}=7.06, Z_{B}=7.24, Z_{C}=6.98 \text { can be calculated. }
$$

4) The analysis on evaluation result

The three evaluation results are sorted as $P_{B}>P_{A}>P_{C}$.Scheme B can be seen as an optimal solution. Consider comprehensively the key indexes of economy, technology and system operation in the construction of distribution centers, and make the most optimal configuration. The enterprise should adopt the scheme $\mathrm{B}$ as planning standards, and the scheme A as an alternative one. The result is stable by using the sensitivity analysis,

\section{CONCLUSION}

Grey fuzzy comprehensive evaluation theory provides a new method for the evaluation of the distribution center planning scheme. Although this method has not been widely used in the planning scheme evaluation, but it has good effect in the distribution center location and other fields. Therefore, there is considerable room for development of grey fuzzy method in the field of logistics, and the method can very well compensate for the limitations of existing models in practice.

\section{ACKNOWLEDGMENT}

The colleagues and friends in Dalian Neusoft Institute of Information give me great help in the process of writing this paper, so express my sincere thanks to them here.

\section{REFERENCES}

[1] Haitao Li, "The application of grey fuzzy theory in choosing the optimal plan of bridge-building project", unpublished.

[2] J.S.Dhillon, S.C.Parti, D.P.Kothari, "Fuzzy decision-making in stochastic multiobjective short-term hydrothermal scheduling”, IEEE Proceedings, Generation, Transmission and Distribution, pp. 79-81, March 2002.

[3] Sifeng Liu, Jianguo Dang, "Grey system theory and applications", Science and Technology Press, Beijing, pp. 68-70, 2004.

[4] Julong Deng, "Basic method of grey system". Huazhong University Press, Wuhan, pp. 55-57, 1987.

[5] Shenghuang Hu, "Multi-level gray evaluation method of subjective index", Systems Engineering Theory and Practice, vol. 1, pp. 15, 1996.

[6] Weizhong Dong, "Planning and design of logistics system”, Electronics Industry Press, Beijing, pp. 100-105, 2006.

[7] Rahuo esh Jain, "Decision making in the presence of fuzzy variables", IEEE Transactions on systems, man and cybernetics, vol. 10, pp. 698703, 1976.

[8] Yonggang Wang, "Evaluation and research of Wanda Group factory site program”, unpublished.

[9] Wenge Liu, "The research on choosing distribution center location based on DHGF theory", unpublished.

[10] Jinghong Xia,Dongrong Xiao,Jingming Xia, “The application of grey relational analysis and AHP theory in choosing logistics center location”, Statistics and Decision, vol. 1,pp. 122-123, 2005. 